\title{
IS THERE ANY EFFECT OF THE TREATMENT ON MVP IN PATIENTS WITH HYPOTHYROIDISM AND HYPERTHYROIDISM?
}

Yildiz Okuturlar ${ }^{1}$, Aliye Soylu² ${ }^{2}$ Enver Tekin ${ }^{1}$, Meral Mert ${ }^{3}$, Serdal Çakmak² ${ }^{2}$ Ozlem Harmankaya ${ }^{1}$, Abdulbaki Kumbasar $^{1}$

${ }^{1}$ Bakirkoy Dr. Sadi Konuk Education and Research Hospital,Department of Internal Medicine, Istanbul, Turkey

2 Bakirkoy Dr. Sadi Konuk Education and Research Hospital, Department of Gastroenterology, Istanbul, Turkey

${ }^{3}$ Bakirkoy Dr. Sadi Konuk Education and Research Hospital, Department of Endocrinology and Metabolism, Istanbul, Turkey

Introduction:

Mean platelet volume (MPV) which is part of a complete blood count measures the platelet size. There are many studies in the literature that it is an indicator of platelet function in thrombotic and inflammatory diseases. However, the number of studies about changes in MVP after treatment in thyroid disease are very limited. In this study, we aimed to reveal the MPV change with treatment in patients with hypothyroidism and hyperthyroidism.
Methods:

Results:

After approval from the ethics committee 400 patients (mean age: $51.24 \pm$ 13.62) were retrospectively examined. Two groups were created as 200 patients ( 21 male ,179 female) with hypothyroidism and 200 patients (26 male, 174 female) with hyperthyroidism. Regularly followed-up patients having no other inflammatory acute and chronic disease and without malignancy were included in the study. Before and after treatment in the outpatient follow MPV and TSH values were compared.

TSH level is found $9.54 \mu \mathrm{lU} / \mathrm{mL}$ and $2.18 \mu \mathrm{lU} / \mathrm{mL}$ pre-treatment and post-treatment period respectively $(p<0.001)$ in hypothyroid patients. Pretreatment TSH level is $0.09 \mu \mathrm{lU} / \mathrm{mL}$ and also post-treatment level is 0.62 $\mu \mathrm{IU} / \mathrm{mL}(p<0.001)$ in hyperthyroidism group. There is significant difference between MPV values before and after treatment in hypothyroidism and hyperthyroidism group and also MPV values increased in both groups after treatment $(p=0.001)$ (Table 1).

Hypothyroidism ( $: 200)$

TSH $(\mu / \mathrm{U} / \mathrm{mL})$ MPV (fL)
Pre-treatment 9.54(4.96-297.1) $8.8(6.1-12.1)$
Post-treatment

2.18(0.5-63.05)
$9.1(7-14)$
Hyperthyroidism (n:200)

p value Pre-treatment Post-treatment p value

0.001

0.001
$0.09(0.001-7.04)$

$8.78(6.7-13)$
$0.62(0.01-19)$

$9(6-12)$
0.001

0.001

Table 1: Comparison of pre- and post-treatment values of TSH and MPV in the groups.

It is known that MPV decreases in inflammatory events and MPV increases with regression of inflammation. Those results of hypothyroidism which is in group of autoimmune thyroid diseases can be interpreted in terms of the presence of inflammation. The reason for the changes in MPV in our study can be explained in terms of the effect of the treatment on inflammatory period. 